\title{
Sobre la especificidad de la derecha radical en América Latina y Perú. De Hitler y Mlussolini a Rafael López Aliaga
}

\author{
Recibido: 10/05/2021 \\ Aprobado: 20/06/2021 \\ Publicado: 31/07/2021
}

\author{
JUAN CARLOS UBILLUZ RAYGADA \\ Universidad Nacional Mayor de San Marcos (UNMSM) \\ Universidad de Texas (UT) \\ jubilluzr@unmsm.edu.pe \\ https:/orcid.org/0000-0002-5775-6816
}

\section{RESUMEN}

El presente artículo problematiza el supuesto parentesco de la derecha radical en Perú y América Latina con el fascismo clásico, e intenta asir su especificidad. Sirviéndose del análisis político, histórico y psicoanalítico, el autor esboza las líneas de (dis)continuidad entre el fascismo, la derecha radical en Europa y Estados Unidos, y la derecha radical en Perú y América Latina. Mientras que aquella puede tener una relación con Hitler y Mussolini, esta tiene como base la tradición colonial y la instauración del neoliberalismo a través del golpe de Augusto Pinochet. Sin embargo, lo que conecta a una y otra derecha radical, y nos permite argüir que estamos hablando del mismo fenómeno (con variaciones), es un delirio paranoico en el que se trata de salvar a la comunidad nacional de un enemigo maligno. Y es precisamente este delirio lo que describe el autor en la campaña de Rafael López Aliaga a la presidencia del Perú, quien lideró una alianza entre neoliberales y evangelistas para luchar contra una conspiración comunista que, con su visión "anti-empresarial" y su "ideología de género", pretendía destruir a un pueblo capitalista y conservador.

Palabras clave: fascismo, derecha radical, psicoanálisis, paranoia, Perú

\section{0n the specificity of the radical right in Latin America. From Hitler and Mussolini to Rafael Lopez Aliaga}

\begin{abstract}
This article discusses the presumed connection between the radical right, in Peru and Latin America, and classical fascism, as well as trying to grasp its specificity. As a result of a political, historical and psychoanalytical analysis the author outlines the (dis)continuity between fascism, the radical right in Europe and USA, and the radical right in Peru and Latin America. Whereas the former might be connected to Hitler and Mussolini, the latter is rooted in the colonial tradition and the introduction of neoliberalism through Augusto Pinochet's coup. However, it's the common paranoid delusion in which the national community must be saved from an evil enemy that reveals the connection between both radical rights, and allow us to identify them as the same phenomenon (with distinctive features). Indeed, this delusion is described by the author as fundamental in the Peruvian presidential campaign of Rafael Lopez Aliaga, who speared an alliance of neoliberals and evangelicals to oppose a communist conspiracy that sought to destroy a capitalist and conservative country through its "anti-business" and "gender ideology" schemes.
\end{abstract}

Keywords: fascism, radical right, psychoanalysis, paranoia, Peru 
C

omienzo a escribir este artículo cuando acaba de confirmarse que Rafael López Aliaga, el candidato de la derecha radical en Perú, no consiguió |pasar a la segunda vuelta electoral del 2021. Pedro Castillo obtuvo el 18.92 \%, Keiko Fujimori el 13.4 \% y López Aliaga el 11.75 \%. de los votos válidos (ONPE 2021). Dado el auge de la derecha radical en América y Europa, lo sorprendente no es que uno de sus candidatos casi pase a la segunda vuelta en Perú. Lo sorprendente es que obtenga tanta votación un candidato tan mediocre como López Aliaga, cuya timidez e incompetencia a la hora de hablar en público lo llevó a tener que recurrir a la lectura en el debate presidencial para la primera vuelta. No estoy demoliendo a este candidato desde una posición política contraria. Sinceramente creo que la mayor parte de sus partidarios estarían de acuerdo en que López Aliaga no tiene ni la mitad del carisma de Silvio Berlusconi o Donald Trump. Esto sugiere que hay un espacio de derecha autoritaria y conservadora en el Perú que puede ser ocupado e incluso ensanchado por otros derechistas radicales, de manera que no es improbable que en un futuro no tan lejano uno de ellos acabe poniéndose la banda presidencial.

Cuando los medios se refieren críticamente a López Aliaga, utilizan a menudo el término fascista. Si este término se asocia a una comunidad racial o étnica unida en torno a un líder fuerte, se hace difícil pensar que un empresario blanco de clase alta sea capaz de convocar de manera fascista a una mayoría mestiza o chola. Quizás habría que prestar atención al término "posfascista" de Enzo Traverso (2018). Pero el problema con este término es que tiene como matriz fundacional al fascismo, y quizás no sea necesario remitirse a este modelo europeo para referirse a un fenómeno que bien podría explicarse recurriendo a nuestras largas tradiciones colonial, oligárquica y/o de dictaduras militares.

El objetivo de este ensayo es esclarecer de qué estamos hablando realmente cuando nos detenemos en personajes como Donald Trump, Viktor Orbán o Marine Lepen, para luego intentar explicar su relación, o no relación, con personajes latinoamericanos como Jair Bolsonaro o López Aliaga. Me serviré para ello de una serie de lecturas de la historia y de las ciencias políticas, pero también del psicoanálisis. Pienso que las cosas se vuelven más claras cuando se consideran no solo las teorías y las prácticas sino los afectos involucrados.

Desde aquí una precisión. Este ensayo se preocupa menos por qué es realmente el fenómeno de la derecha radical que por cómo el líder de esta nueva derecha (si es que es realmente nueva) convoca afectiva e ideológicamente 
a la población. Me interesa, por supuesto, investigar aquello como parte de un proyecto de investigación más largo. Es importante saber, por ejemplo, cuál es la relación efectiva de la nueva derecha con el neoliberalismo: ¿es un intento verdadero de proteger a la nación de los efectos depredadores de las políticas neoliberales, o es un paso hacia un nuevo modelo conservador y autoritario que acabará por destruir lo que queda de democracia, mas no necesariamente al neoliberalismo? Con todo, mi interés en este escrito radica en tratar de entender mejor cómo se constituye el discurso de la derecha radical que moviliza a la población.

\section{El fascismo clásico}

Comencemos por el comienzo, o el supuesto comienzo, el fascismo de Mussolini y Hitler. Según Robert O. Paxton (2004), después de la Primera Guerra Mundial, se presentan cuatro opciones políticas. La primera es el liberalismo clásico con su apuesta por la libertad en términos de derechos individuales y de una economía basada en el laissez faire (la idea de que el Estado no debe entrometerse en el funcionamiento del libre mercado). La segunda es el conservadurismo: si bien en el campo económico podía ser tan capitalista como el liberalismo, en el campo socio-cultural asume que el ser humano es un ser religioso y comunitario, que existe una evolución social "natural" que elude a la planificación racionalista (la comunidad orgánica) y que la desigualdad y las jerarquías son hechos de naturaleza. La tercera es el comunismo, basado en el proletariado como la clase revolucionaria y universal que debe conducir a la humanidad a la sociedad sin clases. Y la cuarta opción, la única de las cuatro que no existía en el siglo XIX, es el fascismo. Más que aludir simplemente a un tema cronológico, quiero subrayar que el fascismo se propone ideológicamente como una " "tercera vía' intermedia entre el capitalismo y el marxismo" (Paxton 2004, 32). Recuérdese que Martin Heidegger consideraba al nazismo como una solución a la pulsión deshumanizadora de la modernidad que se manifestaba como el "comunismo soviético" o el "parlamentarismo británico" (en Olterman 2014).

Sin duda, el fascismo tiene más en común con el conservadurismo que con el liberalismo y el comunismo, pero no es simplemente "una forma más muscular de conservadurismo" (Paxton 2004, 11). Es cierto que, como lo indica Stanley G. Payne $(2014,26)$, había en torno al cambio de siglo una demanda 
por “un sistema autoritario más moderno, técnicamente más eficaz". Pero eso podía haber sido resuelto con un conservadurismo nacionalista que radicalizase un poco más el autoritarismo moderado que acostumbran los conservadores. De hecho, "la aparición del fascismo estimuló una política nacionalista en otras partes de Europa" (Payne 2014, 137) que, sin embargo, no devino en fascismo.

Para hablar de fascismo se tiene que ubicar en el movimiento político conservador un deseo totalitario que trascienda a un simple autoritarismo. Siguiendo a Juan Linz $(2000,161)$, llamo autoritario a un régimen que inhibe el "pluralismo irrestricto" de la participación política democrática y la restringe al "pluralismo limitado" de unos pocos actores tradicionales como, por ejemplo, la Iglesia, el Ejército y la burguesía. Y llamo totalitario a un régimen que concentra los poderes en un partido-Estado, recurre a una ideología medianamente "coherente" y moviliza a las masas a través de los órganos del partido (Linz 2000, 20). No quiero decir con esto que los regímenes fascistas pasaron del autoritarismo al totalitarismo. Los historiadores debaten si en Alemania el partido nazi consiguió o no una concentración total del poder, pero la Italia fascista estuvo muy lejos de ello. Es más, como lo sugiere Paxton (2004, 151-152), el partido de Mussolini se burocratizó en el Gobierno a partir de los años 30, tanto así que su base militante reclamaba que no se estaba avanzando lo suficiente en la creación de una verdadera cultura fascista en Italia. Lo que quiero decir, más bien, es que el fascismo tiene un deseo totalitario de transformar el conjunto de la sociedad, pero que, al llegar al poder, puede seguir su camino hacia el Estado-total, o burocratizarse y/o estancarse en el "pluralismo limitado" de un simple autoritarismo.

Para la crítica marxista ortodoxa, el fascismo fue una respuesta de la burguesía a la gran amenaza del comunismo. Esta tesis no es actualmente muy aceptada por los historiadores, sobre todo porque, como se hace palpable al final del nazismo, el empresariado no estaba nada contento con la escasa lógica económica de las campañas bélicas de Hitler ni con la eliminación de su fuerza laboral barata (el genocidio de los judíos). Hay, en el fascismo, cierta primacía de lo político, cuyo reverso es el rechazo del determinismo económico. Sin embargo, no se puede simplemente invertir la tesis marxista ortodoxa y asumir una no-relación entre el fascismo y la burguesía, pues es un hecho que los grandes empresarios italianos y alemanes se beneficiaron largo tiempo de los regímenes de Mussolini y Hitler. En efecto, el éxito económico alemán se da con la persecución de los sindicatos y la protección de los Konzerne, 
poderosas dinastías industriales que aglutinaban el monopolio de los grandes sectores productivos (Polo Blanco 2019, 70). Como lo sintetiza Jorge Polo Blanco $(2019,63)$, el nazismo persigue a los sindicatos y restablece el "absolutismo patronal" en el seno de la empresa. La famosa unidad orgánica del pueblo en el nazismo se realiza contra la lucha de clases. Por ello, este autor recupera el término "autonomía relativa" para dar cuenta de la relación entre capitalistas y fascistas. No es que la razón de ser del fascismo sea la defensa del capitalismo sino que, históricamente, ha existido un buen acomplamiento entre uno y otro (Polo Blanco 2019, 48).

Convengamos, por lo pronto, en que el fascismo no es solamente un intento de proteger mediante el engaño a los intereses del gran capital ni tampoco una formación política que quiere retornar a los viejos valores sociales (el conservadurismo). De hecho, ni los capitalistas ni los conservadores amaban suscitar el "fervor del pueblo". El fascismo fue una nueva invención para la era de la política de masas que apela a envolver al participante en una mística y en una comunidad ritual (Paxton 2004, 16; Payne 2014, 22). No se trata de que el fascismo quiera ser otra religión. Como lo explica Payne $(2014,21)$, es "una tentativa específica de alcanzar una forma moderna, normalmente atea, de trascendencia. Aunque una manera más contemporánea de decirlo sería: el fascismo es una "religión política" (Maier 2007). En otras palabras, es una organización que transfiere las fuerzas heterogéneas de lo sagrado desde su campo tradicional en la religión hacia el campo secular-moderno de la política. En este sentido, hay en el fascismo un gran apasionamiento por construir una nueva civilización.

El deseo de una civilización nueva se erige históricamente sobre una aprehensión con la decadencia de Occidente (Oswald Spengler), la humillación nacional (el Tratado de Versailles que penaliza a Alemania y frustra las aspiraciones territoriales de Italia), la desintegración de las comunidades por obra del individualismo liberal, y una crisis económica que agrava lo anterior y para la cual no parecía haber una salida tradicional (la crisis posterior a la Primera Guerra Mundial para Italia y la Gran Depresión de 1929 para Alemania). La civilización fascista se basa así en una más potente unión vitalista entre el cuerpo y la cultura, la reinvindicación bélica de la nación humillada y la recreación de un pueblo unido en torno a un líder carismático. De allí que Paxton (2004, 217-218) defina al fascismo como: 
una forma de comportamiento político marcado por la obsesiva preocupación con el declive de la comunidad, la humillación, y con cultos compensatorios de unidad, energía y pureza, en los cuales un partido de masas con militantes nacionalistas comprometidos, trabajando en colaboración tensa pero efectiva con elites tradicionales, abandona las libertades democráticas y persigue con violencia redentiva y sin restricciones éticas o legales metas de purificación interna y expansión externa.

Establezcamos las coordenadas del fascismo en términos psicoanalíticos. En primer lugar, el fascismo tiene al cuerpo vigoroso como un ideal. No se trata simplemente del cuerpo sano, se trata de un cuerpo que se vivifica y potencia a través de su sintonía con otros ideales de la cultura fascista. En otras palabras, hay en el fascismo una combinación de vitalismo e idealismo que se materializa en un cuerpo falicizado ${ }^{1}$ como evidencia de haber superado la decadencia. No es fortuito que Leni Riefenstahl (la mejor cineasta del regimen nazi) haya filmado, en Olympia (1936), los ágiles y potentes cuerpos de la Olimpiada de Berlín. Segundo, el fascismo busca restituir la imagen narcisista de la nación. Muchos historiadores coinciden en que la fecha de nacimiento del fascismo fue 1919, cuando el poeta Gabriele D'Annunzio intentó anexar a Italia la ciudad adriática de Fiume, otorgada a Croacia al término de la Primera Guerra Mundial. Se trataba en este acto de recuperar el orgullo perdido. Jacques Lacan (2003) llama agresividad a la tensión que experimenta el sujeto a partir de su identificación con una imagen narcisista que carece de mediación simbólica. ${ }^{2} \mathrm{Y}$ el acto violento sería un intento de resolver esa tensión que experimenta en el cuerpo. En ese sentido, se podría decir que la guerra en el fascismo apunta a restituir el orgullo perdido de la nación (la imagen narcisista).

Tercero, el deseo fascista tiene como soporte la fantasía-utopía de un pueblo unido, una comunidad orgánica sin divisiones de clase, que adquiere consistencia gracias a su identificación con un líder carismático. Es cierto que a inicios del siglo XX no era extraño oír a intelectuales reclamar por un líder fuerte que resuelva las contradicciones sociales, pero en el fascismo el líder adquiere una dimensión trascedental. Es, una vez más, Leni Riefenstahl

1 Llamo cuerpo falicizado al cuerpo donde se deposita la libido y que funciona como objeto atractor de deseo.

2 "La agresividad es la tendencia correlativa de un modo de identificación que llamamos narcisista y que determina la estructura formal del yo del hombre y del registro de entidades características de su mundo" (Lacan 2003, 102). De hecho, Lacan $(2003,113)$ ubica este fenómeno en la civilización moderna: "La preeminencia de la agresividad en nuestra civilización quedaría ya suficientemente demostrada por el hecho que se confunde habitualmente en la moral media con la virtud de la fortaleza". 
quien captura lo anterior mejor que nadie. Considerada la mejor película de propaganda de todos los tiempos, El triunfo de la voluntad (1935) comienza con el arribo de Hitler a la ciudad Núremberg en un avión de Lufthansa, cual un semidios que desciende desde los cielos, para luego mostrar los cuerpos uniformados de los militantes nazis formando una masa homogénea en torno a un Führer que habla siempre en un podio elevado. En La psicología de las masas, Sigmund Freud (1955a, 122-126) observa que el líder funciona para los integrantes de la masa como un ideal del yo, un punto de identificación vertical. Es esta misma función la que cumple Hitler en El triunfo de la voluntad, donde se le filma siempre en contrapicado. A través de la figura y la voz del líder, la película transmite una voluntad trascendente que convierte a la masa en comunidad.

Finalmente, como lo sugiere Yannis Stavrakakis (1999, 99-112), la utopía del pueblo étnico unido sin divisiones de clase viene de la mano de la fantasía de un agente maligno que impide su cohesión armónica. Puesto que la comunidad armónica es una fantasía ideológica, puesto que esta siempre se tropieza con lo real (una fisura en el sistema), se necesita hallar un enemigo responsable de que la comunidad no sea tan armónica como se pensaba. En el nazismo este enemigo era el judío, que amenazaba con su impureza biológica la buena salud del pueblo ario, o el comunista abocado a la lucha de clases contra un empresariado patriarcal que aseguraba la "solidaridad" entre las clases sociales.

Todo este odio se hace palpable gracias a una película que funciona como contrapunto cómico a El triunfo de la voluntad. En El gran dictador (1940) de Charles Chaplin, el dictador Hinkel de Tosmania se refiere al pueblo judío en un idioma inventado que se asemeja al alemán por sus sonidos guturales. A pesar del carácter ininteligible de este seudoalemán, los gestos y las subidas del volumen de la voz de Hinkel delatan una violenta pasión antisemita (a pesar de que la traductora indica tan solo que "El líder acaba de referirse al pueblo judío"). A lo que voy es que hay algo más en la identificación del pueblo con el líder como ideal del yo. Hay, además, una identificación con una pulsión a la vez liberadora y autoritaria que se dirige contra el enemigo fantasmático. Como lo indica Mladen Dólar (2007, 140), la voz del dictador Hinkel promete "alivio de las restricciones de la ley, 'licencia para matar'; está la promesa implícita de un botín, saqueos, orgía, una promesa de suspender la ley". O más precisamente, la voz del dictador promete la liberación de la ley pública-democrática que prohibe la violencia autoritaria contra los judíos. 
En resumen: la economía libinal del fascismo se basa en el cuerpo falicizado, una agresividad que anhela restituir la imagen narcisista-nacional, el deseo y la fantasía utópica de una comunidad orgánica que obtiene su cohesión mediante la identificación con el líder como ideal del yo, y una pulsión liberadoramente autoritaria que se orienta contra la fantasía del enemigo maligno. Pero todo esto, además, se articula como una paranoia.

Siguiendo a Gilles Deleuze y Felix Guattari (1972-3), podríamos argüir que el fascismo se basa en el delirio paranoico. Hay que entender bien este argumento. Hay dos polos en la psicosis: la esquizofrenia y la paranoia. Mientras que en la esquizofrenia el sujeto se ve aquejado por intrusiones de goce que lo desestabilizan, la paranoia es un intento "enfermo" de curar esas intrusiones. ${ }^{3} \mathrm{O}$, dicho de otro modo, si la esquizofrenia es la experiencia de que el cuerpo se fragmenta, el delirio paranoico es un intento de hacer que el cuerpo consista. Así, por ejemplo, el presidente Schreber (un caso comentado por Freud) se ve sorprendido por un súbito pensamiento que trae consigo un goce perturbador: "Debía ser algo singularmente agradable ser una mujer en el momento coito". Schreber no reconoce este pensamiento como suyo, ni encuentra cómo intregarlo a la representación que tiene de sí mismo. A esto le siguen otros pensamientos (de muerte) y una serie de alucinaciones visuales y auditivas que lo desestabilizan y llenan de angustia hasta que (para abreviar) consigue estabilizarse mediante una interpretación delirante: Dios lo está convirtiendo en mujer para que él/ella (Schreber) pueda dar a luz a una raza schreberiana andrógina que será una versión mejorada de la raza humana.

De vuelta a la política: así como en la paranoia el delirio resuelve la fragmentación esquizofrénica de la realidad subjetiva, en el fascismo la narrativa de lucha contra la conspiración del enemigo maligno pretende hacer consistir una comunidad que se desintegra por los antagonismos sociales o por el propio movimiento esquizoide del capitalismo. ${ }^{4}$ El comunismo, por ejemplo, desplaza los afectos desde la vieja unidad nacional (padre-patrón-patria) hacia la lucha de clases u otro tipo comunidad (la sociedad sin clases). Y en el capitalismo la producción y la circulación se modifican constantemente y los flujos

3 El psicoanalista Daniel Millas $(2015,25)$ sostiene, por ejemplo, que "el delirio es la construcción de una nueva realidad, que opera no solo con el sentido, sino también con lo pulsional. [...] el delirio solo es eficaz cuando logra establecer una regulación del goce que afecta al sujeto".

4 Deleuze (2005: 77) observa que mientras que el polo paranoico "opera la gran sobordinación de las máquinas deseantes a los aparatos de los grandes conjuntos", el polo esquizofrénico "opera la subordinación inversa, la subordinación de los grandes conjuntos molares a las formaciones moleculares". 
del capital obedecen a la lógica nacional. Cuando Deleuze y Guattari (1972-3, 292) afirman que "nuestra sociedad [capitalista] produce esquizos", no hacen más que repetir en lenguaje psicoanalítico aquello que Marx y Engels (2014, 12) ya habían observado en el Manifiesto comunista:

\begin{abstract}
La burguesía no puede existir sino a condición de revolucionar incesantemente los instrumentos de la producción y, por consiguiente, las relaciones de producción, y con ello todas las relaciones sociales. [...] Todas las relaciones estancadas y enmohecidas, con su cortejo de creencias y de ideas veneradas durante siglos, quedan rotas; las nuevas se hacen añejas antes de haber podido osificarse. Todo lo estancado y estamental se esfuma, todo lo sagrado es profanado, y los hombres, al fin, se ven forzados a considerar serenamente sus condiciones de existencia y sus relaciones recíprocas.
\end{abstract}

Sin duda, este pasaje goza de una gran actualidad, pero habría que acotar que si bien la desacralización del mundo puede llevar al ser humano a "enfrentar serenamente sus condiciones de existencia", también puede llevarlo a vivirlas con temor y angustia. Los capitanes de industria pueden saludar el advenimiento de un nuevo mundo, pero muchos viven con desesperación la desintegración de sus viejos lazos comunitarios y medios de subsistencia. Es entonces que aparece el delirio fascista para dar sentido a las fuerzas disgregadoras del mundo moderno. La teoría conspirativa permite crear una ficción localizada de los enemigos. Ya no se trata de las fuerzas anónimas del mercado o de la política democratizadora. Ahora se trata de un enemigo maligno que aspira a dañar la comunidad.

Una advertencia. Mi análisis psicoanalítico no intenta patologizar el fascismo. Al hablar de paranoia, no quiero decir que los militantes fascistas sean locos. Hay una diferencia entre decir que un discurso o un lazo social es psicótico y decir que sus individuos son psicóticos. En El malestar de la cultura, Freud $(1955 b, 81)$ califica de "delirio de masas a las religiones de la humanidad", pero no extiende el diagnóstico de paranoia a los feligreses. Y segundo, para Lacan hay en el mundo neuróticos, psicóticos y perversos, pero nunca individuos normales. Así, cuando sugiero que el fascismo es un lazo social paranoico, no pretendo contrastarlo negativamente a la normalidad de la democracia liberal. Pero sí quiero señalar que, en tanto que su delirio se basa en una reivindicación narcisista y fantasmática contra un "otro" maligno, se encuentra más cerca al acto violento. 


\section{EI posfascismo o la derecha radical}

En Las nuevas caras de la derecha, Enzo Traverso utiliza la noción de posfascismo para dar cuenta de un fenómeno político contemporáneo que tiene líneas de continuidad y discontinuidad con el fascismo de la primera mitad del siglo XX. Para él, esta noción "ayuda a describir un fenómeno transitorio, en transformación, que todavía no ha cristalizado" (Traverso 2018, 17-18). El autor se refiere a una derecha que se ha emancipado del fascismo clásico, aunque "en la mayoría de los casos lo conserva como matriz" (Traverso 2018, 18). Así, por ejemplo, el Frente Nacional de Jean-Marie Lepen tiene como matriz indiscutible al fascismo francés. Pero a partir de los años noventa del siglo pasado, el Frente empieza a evolucionar políticamente hasta dar un gran salto en el 2011, con la llegada de Marine Lepen (hija de Jean-Marie) a su jefatura. Sus referencias ideológicas cambian y "ahora se preocupa por su respetabilidad, procura integrarse al sistema de la Quinta República mediante la propuesta de protagonizar una alternancia política 'normal', indolora" (Traverso 2018, 20).

Para Traverso (2018), si bien los los partidos posfascistas son autoritarios, y pueden transgredir los límites de la democracia, por el momento no hay una ruptura clara con ella. Ni siquiera en la Hungría de Viktor Orbán. Es cierto que Mussolini y Hitler llegan al poder mediante la vía legal, pero su voluntad de derribar el estado de derecho y borrar la democracia estaba fuera de discusión (Traverso 2018, 20). Como bien lo señala Traverso $(2018,20)$, el fascismo clásico pretendía "cambiarlo todo", mientras que el posfascismo parece querer "transformar el sistema desde adentro". Nada garantiza que los partidos posfascistas destruyan finalmente el estado de derecho democrático, pero, precisamente, el término posfascismo describe un "fenómeno transitorio, en transformación".

Aquí es importante recalcar que mientras el fascismo tenía una pretensión revolucionaria (la creación de una nueva civilización), el posfascismo es más bien reaccionario. No solo porque no predica abiertamente la toma del Estado por asalto ni está enamorado de la expansión militar (Trump, por ejemplo, se opuso mal que bien a la guerra en Irak), sino porque sus recetas políticas son regresivas y hasta nostálgicas: "Postulan el restablecimiento de las soberanías nacionales, la adopción de formas de proteccionismo económico y la defensa de las identidades nacionales amenazadas" (Traverso 2018, 39). 
Alberto Toscano (2020) concuerda con esta elaboración. Para él, el "fascismo contemporáneo" no cuenta con el elemento "fanático-religioso" del fascismo clásico (Toscano 2020, 37). En otras palabras, el posfascismo no es una "religión política", que ha transferido las fuerzas de lo sagrado desde la religión a la política secular. No hay en él el "exceso libidinal" del fascismo, "excepto en la forma vestigial de lo que podríamos llamar el "líder obsceno"" (Toscano 2020, 37). Pero, además, su propuesta utópica se mimetiza con:

la nostalgia por la imagen de un momento (ese de la afluencia de la posguerra, de los trente glorieuses), de una imagen racializada y genérica del obrero industrial patriótico socialmente reconocido (el obrerismo nacionalista de Bifo podría también ser llamado fordismo nacional o racial, el que curiosamente reprime las condiciones regulatorias estatales de esta fantasía) (Toscano 2020, 36-37).

Cas Mudde (2019) también distancia este nuevo fenómeno político de las experiencias de Hitler y Mussolini. De allí que, a pesar de reconocer que parte de ese fenómeno tiene una matriz fascista, escoge un término neutro como "derecha radical populista" (de ahora en adelante, por comodidad, "derecha radical"). Aceptemos por lo pronto este cambio de terminología, ya que no es seguro que la nueva derecha en América Latina tenga mucho que ver con el fascismo.

Hay, según Mudde (2019), tres momentos previos a la consolidación de la derecha radical contemporánea. El primero (de 1945 a 1955) es el neofascismo, el cual no tiene mucho de nuevo porque es un remanente de la vieja ideologia fascista. El segundo (de 1955 a 1980) es el populismo de derecha, el cual se alza contra la marginación rural y el desarrollo del estado de derecho. Y el tercero (de 1980 al 2000) es la aparición de la derecha populista, la cual participa en elecciones con éxito relativo y se va convirtiendo en la visión dominante de la far right. La diferencia del tercer momento con el actual es que la derecha radical se ha vuelto parte del mainstream No solo consigue ganar un buen número de escaños en el Parlamento, y hasta elecciones presidenciales o de premierato, sino que se vuelve aceptable para coaliciones con la derecha tradicional y esta, a su vez, asume las propuestas radical-derechistas de manera moderada.

La derecha radical tiene tres características principales: es nativista, autoritaria y populista. Su nativismo no es de carácter racial-biológico, como en el nazismo, sino de carácter etnocrático. Se asume la existencia de un pueblo étnico y un vínculo natural entre este y la nación. Su autoritarismo se sos- 
tiene en la creencia en una sociedad estrictamente ordenada en la cual las transgresiones a la autoridad deben ser castigadas con severidad. Y su populismo (como el de todo populista, ya sea de izquierda o derecha) consiste en una "ideología delgada" para la cual la sociedad está separada entre dos grupos homogéneos y antagonistas, vale decir, entre el pueblo y la elite corrupta (Mudde 2019, 32).

Según Mudde $(2019,35)$, la derecha radical coge impulso en Europa luego del ataque terrorista a las Torres Gemelas en el 2001, la gran crisis finaciera del 2008 y la crisis de refugiados en el 2015. De estas tres crisis surgen tres temas para la derecha radical que se encuentran entrelazados: la inmigración, la idea xenófoba de que Occidente está amenazado por la inmigración islámica; el aumento en la criminalidad, ya sea en la forma del terrorismo o de la delincuencia común; y el reclamo de soberanía contra la globalización o la comunidad europea. Hay un cuarto tema que se entrelaza también con el anterior: la corrupción. Hay, para la derecha radical, una elite corrupta sin ningún compromiso con la nación que permite que esta sea "invadida" por los inmigrantes y "coactada" por empresas e instituciones internacionales, pero también por ideologías foraneas, ajenas al desarrollo "natural" del pueblo, como, por ejemplo, el enfoque de género.

Dicho esto, dada la emergencia en los últimos años de la lucha por el derecho al aborto y contra el feminicidio (Ni Una Menos), el acoso sexual (Me Too), así como las diversas marchas pro-LGTBI (el orgullo gay y otras), el tema de género no puede tratarse simplemente como subsidiario de la corrupción. Es más, podría adelantarse la hipótesis de que la agenda política y cultural en torno a la mujer y los gays es, para la derecha radical, tan central como el nativismo. En cualquier caso, tanto la tolerancia multicultural como la "ideología de género" son, para esta derecha, expresiones del "marxismo cultural".

No sería ocioso detenerse en este término. Como lo explica Slavoj Zizek (2020, 271), la alt-right asume que:

después del fracaso del comunismo como sistema económico y el hecho de que no hubo revolución en el Occidente desarrollado, los marxistas decidieron desplazarse hacia el dominio de la cultura y la moralidad, y de este modo nació el "marxismo cultural". Su objetivo es corroer la columna vertebral de nuestras sociedades y así poner en movimiento la debacle final de nuestras libertades. 
Por supuesto, el marxismo cultural no existe; no es más que un chivo expiatorio de la derecha. Como lo aclara Alejandro Bermeo (en Stefanoni 2021, 82), es "una excusa a la desintegración del conservadurismo cultural, a sus tradiciones, sus visiones sobre la familia, el matrimonio, el aborto y el lugar de la mujer en la sociedad; no en vano, es imperativo ponerles la etiqueta 'marxismo', aunque no lo sea, para mantener vivo ese sentimiento políticamente útil de terror histórico al comunismo de Occidente". En ese sentido, el término marxismo cultural aspira a asociar las demandas de igualdad de la mujer y de los grupos LGTBI con la violencia revolucionaria y hasta el totalitarismo. Y a su vez, el término ideología de género asocia la crítica del enfoque de género al patriarcado (basado en genealogías foucaultianas y butlerianas) con una herramienta política y un conjunto de creencias erradas.

Sintetizando lo anterior, la derecha radical covoca al pueblo a una lucha contra una elite corrupta que apoya una política neoliberal y una agenda social progresista que ha llegado hasta las escuelas públicas. Y la neolengua orwelliana de esta elite progresista (una lengua inventada por la hegemonía progresista lejos de los "problemas reales de la gente") es la corrección política. De allí que los partidarios y el líder de la derecha radical se empecinen en "decir la verdad", lo cual implica en la práctica ser políticamente incorrecto y a menudo obsceno. Según Stefanoni (2021, 70), la derecha radical se ha apropiado de la fuerza subversiva y popular de la izquierda: "La transgresión cambia de bando: es la derecha la que dice 'las cosas como son', en nombre del pueblo llano, mientras que la izquierda - culturalizada - sería solo la expresión del establishment y del status quo". En otras palabras, "la izquierda culturalizada" representa la agenda progresista de una elite cosmopolita - la famosa “izquierda brahmánica” de Thomas Piketty—, mientras que la derecha radical deviene la expresión tosca del pueblo.

Stefanoni (2021) tiene razón en que la derecha radical se ha apropiado de la "transgresión" de la izquierda revolucionaria. Hay, en esta nueva derecha, una satisfacción pulsional a la vez liberadora y autoritaria en transgredir las normas de la correción política y afirmar "las verdaderas creencias del pueblo". Si la corrección política puede funcionar como una imposición superyoica de las elites "civilizadas", la derecha radical pretende ser la gesta liberadora-autoritaria de un pueblo que aspira a restaurar la tradición conservadora.

En su versión más eficaz, la pulsión autoritaria-liberadora se traduce en politicas públicas precisas (las políticas inmigratorias de Trump y Orbán, por ejemplo). Pero, en su versión más espectacular, apunta a una satisfacción más 
cercana al consumo mediático. Es un hecho que si bien la mayoría de medios de comunicación odiaban a Trump, por el otro, amaban cubrir cada uno de sus dichos ofensivos. Según Alain Badiou (2020, 31-32), Trump es un síntoma de que el estabishment bipartidista ya no puede capturar el deseo político de las masas. Pero también puede ser un síntoma de que la política se ha convertido en un carnaval en el que la masa da rienda suelta a su agresividad sin ningún rumbo político.

Sin embargo, hay que recordar que la agresividad de la derecha radical no tiene el "fervor religioso" del fascismo clásico. Así como el fascismo, la derecha radical pretende restaurar la imagen narcisista nacional: piénsese en el "Make America Great Again" de Trump. Y así como aquel, este tiene el deseo y la fantasía de una comunidad orgánica. Mas lejos del deseo fascista de fundar un nuevo orden, la derecha radical ubica su comunidad idílica en el pasado mítico de los hombres blancos del capitalismo fordista, cuando los obreros eran todos hombres y blancos porque no había ocurrido aún la "invasión de los extranjeros", ni las mujeres ni los gays habían trastornado el orden natural de las cosas. No hay, por tanto, en la derecha radical, una fascinación con construir el reich de los mil años. Como ya lo había adelantado Toscano (2020), hay más bien una mirada nostálgica.

Por otra parte, así como el fascismo, la fantasía de la comunidad orgánica viene de la mano de la fantasía del enemigo maligno. Si otrora este era en Europa el judío, ahora es el musulmán. Pero tanto ayer como hoy el enemigo es también el comunista. Solo que esta vez persigue una mañosa revolución cultural. Hay, además, como en el fascismo, una identificación con un líder carismático a través del ideal. Algunos líderes como Viktor Orbán, que luchó contra el comunismo en Hungría, se postulan como un ideal del yo (un ideal que implica el sacrificio "adulto" del goce o del placer en nombre de la ley). Pero otros como Berlusconi y Trump encarnan más bien un ideal de éxito en el cual co-existen el ideal del yo con el yo-ideal (un ideal infantil, narcisista, que no implica sacrificio alguno). Para ser más claro, Trump y Berlusconi pueden funcionar como ideales del mundo empresarial (ideal del yo), pero a la vez como ideales de consumo de placer sexual y de objetos lujosos (yoideal). ${ }^{5}$ Por eso mismo, la identificación con el líder asume a veces una tonalidad más vulgar. Berlusconi, por ejemplo, no ocultaba sus impulsos sexuales y Trump se llegó a burlar de un individuo con discapadidad. Mussolini y Hitler

5 Sobre la diferencia entre ideal del yo y el yo-ideal, ver Indart (1999). 
podían exhibir su odio a los judíos, pero no mostrarse vulgar en el sentido más "grasoso" del término.

Finalmente, así como en el fascismo, hay en la derecha radical una estructura paranoica. Se trata de una interpretación delirante que se sirve de la narrativa de reivindicación narcisista y de las teorías conspirativas para hacer consistir a la comunidad nacional. Pero, al menos por el momento, el delirio se encuentra acotado por los acuerdos internacionales, el mercado global y la democracia. Los proyectos de expansión militar son menos importantes para la derecha radical que en el fascismo clásico. Trump, por ejemplo, fue un presidente mucho menos belicista que los "halcones republicanos" e incluso que demócratas como Hillary Clinton. Y su publicitada guerra comercial contra China acabó en un armisticio sin consecuencias reales. Por su parte, Viktor Orban ha construido un capitalismo nacional e intenta afirmar su soberanía ante la Unión Europea, pero hasta ahora continúa dentro de ella. Sin duda hay en él un giro autoritario a recortar derechos sociales de todo tipo, pero su "democracia iliberal" (donde, por ejemplo, se violan los derechos civiles de las minorías) está lejos de ser el Estado totalitario. Al menos por el momento, Orban se maneja dentro de un sistema intermedio entre autoritarismo y democracia que Steven Levitsky y Lucan A. Way $(2004,159)$ llaman "régimen autoritario competitivo", es decir, un regimen en el cual "las instituciones democráticas formales son ampliamente vistas como medios principales para obtener y ejercer la autoridad política".

Todo esto suscita una pregunta: ¿qué impide que lo derechistas radicales se independicen más claramente de los acuerdos internacionales, la lógica económica y las formas democráticas? Sin negar que en el futuro la derecha radical mande todo esto al tacho, podría decirse que hay dos factores entrelazados que lo inhiben de hacerlo. El primero es una menor fuerza utópica debido a su carácter nostálgico. Puede existir en esta derecha mucho ruido y furia revindicativos, la rabia y la venganza contra un "otro" malo que "me quita lo mío", pero no la pretensión fascista de fundar una nueva civilización. De allí que el racismo de la derecha radical pueda estabilizarse como etnopluralismo (Mudde 2019, 26), el cual no se propone (al menos explicitamente) como un racismo expansivo, sino como una perversa defensa multicultural del derecho de cada etnia a reclamar como suya la nación. Y el segundo factor es que existe hoy en día (a diferencia de los tiempos del fascismo clásico) una mayor importancia histórica del mercado global, los regímenes democráticos y los acuerdos internacionales. $\mathrm{O}$, para ser más preciso, la mayor importancia 
de la lógica económica de la globalización hace que, para no ser excluidos de esta o penalizados con sanciones o embargos, los países en Occidente quieran preservar una apariencia democrática y también cierto respeto de los acuerdos internacionales.

Hay algo a la vez duro y flexible en la derecha radical contemporánea. Por un lado, hay una identificación dura con el proyecto de una nación étnica que contradice la democracia y los acuerdos. A menudo esto viene de la mano con una identificación con una moral sexual tradicional. Pero, por el otro lado, hay cierta flexibilidad para transgredir respetando la democracia y los acuerdos internacionales. El Brexit, sin embargo, implicó una transgresión más clara y abierta. Pero, como lo sostiene Mudde (2019, 124-125), sus pésimos resultados han conseguido que pocos partidos relevantes de la derecha radical quieran imitar al Reino Unido en su deseo de salirse de la Unión Europea. En este sentido, se podría argüir que el delirio paranoico se halla acotado por la globalización capitalista en tanto principio de realidad. Si algo caracteriza a los radicales de derecha, es la paradoja de que el frío cálculo capitalista convive con el delirio "reaccionario" de restaurar una comunidad en proceso de disolución por obra del capitalismo global.

\section{La derecha radical en América Latina}

El posfascismo o el fascismo contemporáneo son términos que pretenden dar cuenta de un fenómeno en Europa y en Estados Unidos que depende, en gran parte, de un hecho sociológico: hay una mayoría étnica blanca que se identifica con la nación y resiste la "intrusión" de una minoría étnica no-blanca. ¿Pero cómo podría eso funcionar en América Latina, donde la etnia blanca es una minoría con respecto a una mayoría mestiza o indígena? Para tener un "verdadero" posfascismo en el Perú, se necesitaría, por ejemplo, un grupo indígena-mestizo empoderado que resista la inmigración de otras etnias. O, para ser más claro, debería haber un líder cholo que covoque a una mayoría chola a apostar por una nación chola contra la inmigración de una minoría nochola a la que se considera peligrosa. Pero no es eso lo que ha sucedido con López Aliaga en Perú. Ni nada análogo ha sucedido tampoco con Bolsonaro en Brasil y otros exponentes de la derecha radical en América Latina.

Por otra parte, como lo sugieren Stumpgf, González, Baquero y Mullo Grohmann $(2020,648)$ para el caso de Brasil, hay una tradición conservadora 
autoritaria más antigua que la matriz fascista de la derecha radical. En otras palabras, una derecha autoritaria y conservadora no habría venido a erosionar la democracia liberal en Brasil, porque los principios del liberalismo nunca se habrían instaurado en la cultura política brasileña y esta habría tenido siempre una tendencia conservadora y autoritaria. De manera similar, en "De encomenderos a neoliberales", Nicolás Lynch $(2020,4)$ se enfoca en la tradición de la derecha peruana: su artículo no apunta a explicar el posfascismo o la derecha radical, sino el surgimiento de la derecha neoliberal en el siglo pasado, la cual describe en parte como vieja por "su carácter oligárquico, colonial, racista y patrimonialista". Pero también podría decirse lo mismo de la derecha radical latinoamericana. $\mathrm{O}$, para ser más claro, debido a los remanentes del colonialismo en America Latina, la derecha radical no necesita un modelo "extranjero" como el fascismo para aplastar los derechos de algunos ciudadanos de la nación.

El artículo de Lynch (2020) nos permite, además, pensar en un continuum entre el colonialismo y una tradición más reciente. En consonancia con Francisco Durand y otros investigadores, Lynch $(2020,5)$ señala que en el Perú la derecha ha establecido una nueva hegemonía política en los últimos treinta años, pero "no lo ha hecho como antaño con una invocación general a su carácter de elite que, por diversas razones, de propiedad y/o intelecto, tendría el derecho a mandar, sino con un programa muy claro de reorganización de la sociedad y el Estado, en contraste con la realidad anterior de crisis que buscaba dejar atrás". Así, lo nuevo en la derecha peruana sería la producción de una hegemonía neoliberal que limita la intervención estatal en la economía $\mathrm{y}$, a la vez, convoca a los peruanos a pasar de ciudadanos a emprendedores y consumidores. Otrora, decir que "Perú es una marca" habría hecho rabiar a la mayoría de los peruanos, pero hoy hasta un candidato de la "izquierda dura" como Pedro Castillo se anima a vestir una casaca de buzo con el logo Marca Perú.

Por supuesto, esto no es ni específicamente peruano o latinoamericano, sino una tendencia mundial que se origina en Chile, se desarrolla en Inglaterra y Estados Unidos, y que, para los países en desarrollo, adquiere un carácter normativo con las reformas del Consenso de Washington y su apuesta por la disciplina fiscal, la desregulación finaciera, la liberalización del comercio, la eliminación de subsidios, la privatización de empresas estatales, etc. Sin embargo, es precisamente en este punto donde se encuentra una diferencia entre el fenómeno de la derecha radical en América Latina, y en Europa y 
Estados Unidos. En los años noventa, Bolsonaro consideraba que el presidente Henrique Cardozo debía ser ejecutado por privatizar las empresas estatales, pero como candidato a la presidencia en el 2018 puso a su lado al "Chicago boy" Paulo Guedes como futuro ministro de Economía y, cuando asumió la presidencia, retomó las privatizaciones. Asimismo, en la primera vuelta electoral del 2018, en Costa Rica, el candidato de Restauración Nacional Fabricio Alvarado postuló como representante de los olvidados de la tierra, pero en la segunda vuelta se rodeó de un equipo económico con una "estrategia de acumulación neoliberal" que respondía a los intereses de los grupos dominantes (Arias 2018).

Entonces, una diferencia crucial entre la derecha radical en Europa y Estados Unidos, y aquella que surge en América Latina, es que mientras la primera se opone al neoliberalismo, la segunda propone su continuación. Contra esto se podría argumentar que algunos líderes de la derecha radical no son tan opuestos al neoliberalismo. Trump, por ejemplo, llegó al poder con una retórica nacionalista, pero sus políticas económicas basadas en la desregulación, la reducción de impuestos a las corporaciones y el ataque a los derechos de los trabajadores y sus sindicatos se hallan en perfecta sintonía con el proyecto neoliberal. Sin embargo, lo que me interesa en este escrito no es si los radicales en Europa y Estados Unidos superan realmente el modelo económico neoliberal, sino cómo recurren a un discurso anti-neoliberal para convocar a la población a resolver sus crisis o problemas.

En ese sentido, lo particular de nuestra derecha radical tiene como matriz histórica cercana (no al fascismo europeo sino) a la dictadura de Augusto Pinochet, en Chile, la cual inaugura el neoliberalismo en el mundo. En otras palabras, la matriz histórica más cercana de la derecha radical latinoamericana es la de un acomplamiento entre un tradicional Gobierno militar autoritario que llega al poder mediante un, igualmente tradicional, golpe de Estado para alejar a los "comunistas" del poder, y la instauración de un nuevo modelo económico, social y estatal que lleva el nombre de neoliberalismo. O dicho aún de otro modo, el autoritarismo militar de Pinochet pretendía devolverle al cuerpo social su "natural" desarrollo orgánico dentro de un orden jerárquico pre-existente (conservadurismo) y a la vez servir de laboratorio del mundo para un nuevo sistema socio-político.

Por supuesto, el golpe del 11 de septiembre de 1973 fue solo el comienzo. Después de que Inglaterra y Estados Unidos asumieran con "éxito" durante la década de los ochenta el modelo neoliberal, este se trasladó nuevamente a 
América Latina durante los noventa. En algunos países (Argentina, Bolivia y Perú) se aplicaron estas reformas más que en otros (Ecuador y Venezuela). Y si bien aquellos pudieron inclinarse hacia el autoritarismo, no se puede decir que sus gobernantes hayan roto por completo con la democracia formal. A lo más se podría decir que, en algunos de estos países, como en el Perú de Alberto Fujimori, por ejemplo, se practicó un autoritarismo competitivo (Levitsky y Way 2004).

Según Gabriel Papa $(2004,8)$, a pesar de que “tuvieron éxito en remodelar sustantivamente el aparato productivo de la región, profundizar la inserción internacional basada en los productos primarios y en consolidar una nueva forma y estructura del Estado, [...] las políticas neoliberales fracasaron en su promesa de mejorar sustantivamente la situación social de las mayorías e inaugurar una nueva era de crecimiento sustentable". Y la respuesta limitada a este fracaso exitoso es la "marea rosa", que comienza con la elección de Chávez en Venezuela (1998) y continúa en Brasil, Uruguay, Bolivia, Chile y Ecuador. Entre la socialdemocracia y el neodesarrollismo, los países de la marea rosa han conseguido disminuir la pobreza, pero sus resultados han sido más modestos de lo esperado. Sergio Costa y Frances Badia (2018) señalan, por ejemplo, que el socialismo del siglo XXI no ha conseguido disminuir la concentración de ingresos ni impedir "la apropiación del Estado y de la política económica". Por esta y otras razones, se ha dado en la segunda década del siglo XXI "el ocaso del ciclo de Gobiernos de izquierda en la región", el cual es sustitutuido, como por lo general ocurre, "por una marea de derecha" (Pereira da Silva 2018, 63).

Es como parte de esta marea que debería ubicarse el fenómeno de la derecha radical. En El eterno retorno, Farit Kahhat (201) establece raudamente esta relación. Para él, mientras que la derecha radical en Europa surge con el declive electoral de la izquierda tradicional (la socialdemocracia), en América Latina "crece en un contexto en el cual la región tenía el mayor número de Gobiernos de izquierda en toda su historia, y tiene en la confrontación con el regimen de Venezuela una causa común" (Kahhat 2019, 157). Hay, sin embargo, un límite a esta tesis. Concuerdo con que un nuevo autoritarismo de derecha habría vuelto para poner en marcha el tren neoliberal interrumpido por la marea rosa, ¿pero por qué llamar a eso derecha radical? Según Mudde (2019), una derecha radical es nativista, autoritaria y populista. El neoliberalismo puede ser autoritario y populista, pero no necesita remitirse a una comunidad étnica u orgánica, o a cualquier otro tipo de comunidad cerrada. Basta con 
apelar al deseo de distintos individuos emprendedores. Tiene que haber algo más que el autoritarismo para convertir al neoliberalismo en derecha radical.

Es allí donde entra en juego el acoplamiento entre los neoliberales y los evangélicos pentecostales y neopentecostales. Tanto en Chile y Costa Rica, como en Brasil y Perú, los candidatos de la derecha radical han sido apoyados por una coalición formada por "revolucionarios" neoliberales y conservadores cristianos. Y es precisamente esta alianza lo que permite hablar de cierto parentesco entre la derecha radical de América Latina y la de Europa y Estados Unidos. En otras palabras, la derecha de aquí comparte con la de allá un discurso que convoca a un pueblo cristiano y/o conservador a luchar contra el aborto, el matrimonio homosexual, el enfoque de género en los colegios, etc. O, dicho aún de otro modo, ambas derechas radicales comparten el llamado a salvar a una comunidad moral de una perversa "ideología de género" impuesta por una elite progresista.

En un artículo reciente Kahhat (2021) sostiene que una diferencia entre la derecha radical europea y la latinoamericana es que la lucha contra "la ideología de género" es parte de "una agenda política no negociable". En Francia, por ejemplo, muchos partidarios del Frente Nacional pueden odiar a los homosexuales, pero Marine Lepen ha utilizado la aceptación oficial de su partido del matrimonio homosexual como un arma ideológica republicana contra los inmigrantes musulmanes, supuestamente machistas y homofóbicos. Y en Holanda, Pim Fortuyn era un dandy homosexual que irónicamente llamaba a suprimir el primer artículo de la Constitución, el cual prohibía cualquier tipo de actitud discriminatoria. Kahhat (2021) tiene razón en que nada de esto sería posible en América Latina o en Estados Unidos, ya que el rechazo a la "ideología de género" es un nucleo ideológico fuerte de los grupos religiosos. Sin embargo, es precisamente este rechazo lo que nos permite pensar que estamos hablando del mismo fenómeno político. O más, precisamente, es la lucha reaccionaria contra este componente clave del "marxismo cultural" la que conecta a los derechistas radicales en América Latina con los de Europa y Estados Unidos.

Por cierto, el término "marxismo cultural" ha ganado terreno en América Latina. En Brasil, por ejemplo, Ernesto Araújo y Olavo de Carvalho (dos gurúes del bolsonarismo) lanzan invectivas contra los filósofos de la Escuela de Frankfurt, a quienes consideran los padres de la actual conspiración marxista a escala planetaria. Y, vinculada con el Ministerio de Relaciones Exteriores de Brasil, la Fundación Alexandre Gusmao "apela a una estrategia internacional 
en la que dice combatir el comunismo y el abortismo, a los que considera pilares del "marxismo cultural"' (Arantes 2000). Pero lo que se advierte tanto en Brasil como en el resto de América Latina es que este término tiende a reincorporarse a aquel que le da origen: el marxismo o, mejor, el comunismo. Como se señaló arriba, el comunismo no está tan muerto en América Latina como en Europa y Estados Unidos. No ha habido una marea roja como lo creen los derechistas radicales en el continente, pero sí una marea rosa en la cual Marx y Lenin volvieron a ser referencias habituales de algunos de sus líderes.

Así, el derechista radical latinoamericano se sirve del viejo término "comunista" para condenar cualquier intervención política que atente contra los valores familiares patriarcales y heterosexistas, y contra el neoliberalismo. Pero este término se emancipa de su contexto histórico y se convierte en un significante que condensa negativamente a todos aquellos que se oponen a la unidad interclasista de una nación conservadora y neoliberal. En otras palabras, "comunista" no solo califica a la gran variedad de políticos de izquierdas sino también a feministas, ecologistas e incluso neoliberales que afirman una agenda cultural progresista. Se trata de una operación ideológica que agrupa muy distintos actores sociales dentro de un significante que se remite, sin embargo, a una misma escena fantasmática: el ataque virulento y artificioso a una familia-nación patriarcal y capitalista.

La derecha radical en América Latina nos remite a la fantasía utópica de una comunidad anterior al ataque de los comunistas. Así como las derechas en Europa y Estados Unidos tienen una utopía reaccionaria. No nos remite a un pasado mítico del capitalismo fordista, porque nunca lo hemos tenido, sino a una nación cristiana/conservadora y capitalista cuyo correlato histórico no es otro que la vieja oligarquía latinoamericana. Se quiere una América Latina anterior a los partidos de masas de izquierda. No obstante, junto a esta utopía que se erige sobre una velada tradición oligárquica, colonial y racista, hay también una con empuje hacia el futuro: la de ser "ciudadanos" de una nación que se ha insertado plenamente en el capitalismo global. Quienes se adhieren a la derecha radical latinoamericana no son solo quienes añoran por los viejos tiempos inexistentes de una familia-nación cristiana y capitalista. También están quienes anhelan ser parte de una nación bien inscripta en el capitalismo global y cuyos ciudadanos se desplazan por el mundo a sus anchas.

Hay, además, en esta construcción latinoamericana una identificación con un líder carismático a través del ideal y de la pulsión. Sin negar los lazos 
de estos líderes con el ideal, a veces destaca la identificación pulsional con el odio y la vulgaridad del líder. Quienes, por ejemplo, se identifican con Bolsonaro, alcanzan una gran satisfacción escuchándole decir a Maria do Rosario, diputada del Partido de los Trabajadores: "Jamás te violaría, ya que usted no lo merece [por ser muy fea]", o decir a bocajarrro cosas como "El error de la dictadura fue torturar y no matar [a los comunistas]". No puedo determinar si la intensidad de este discurso del odio es parte de la tradición colonial latinoamericana, un recurso espectacular del mundo contemporáneo, una característica propia de Bolsonaro, o las tres cosas a la vez. Pero hay allí una satisfacción en la violencia verbal que no se encuentra en los actuales líderes de la derecha radical de Europa y Estados Unidos.

Finalmente, como se intuye, todo lo anterior se articula dentro de una estructura paranoica. El delirio apunta a recomponer la familia-nación contra los ataques del enemigo comunista. Como se ha visto, estos ataques vienen desde dos frentes: desde la marea rosa y desde la ideología de género. Y, como se ha sugerido, es la defensa contra este último ataque la que conecta a la derecha radical de América Latina con la de Europa y Estados Unidos. O, más claramente, en todas partes del mundo la derecha radical lucha por resarcir el tejido patriarcal de la sociedad contra un elemento femenino que osa salirse de su lugar tradicional.

A fin de darle mayor sustento a lo que vengo de exponer, quiero concentrarme en el candidato a la presidencia del Perú en el año 2021, Rafael López Aliaga del partido Renovación Popular.

\section{Rafael López Aliaga contra la conspiración caviar}

Dentro de la derecha radical, López Aliaga tiene un parentesco evidente con Silvio Berlusconi y Donald Trump. No es un político tradicional sino un empresario, o mejor aún, un magnate que ingresa a la política para supuestamente gobernar al país con visión y eficiencia empresarial.

López Aliaga empieza a hacer su fortuna con las privatizaciones del Gobierno de Alberto Fujimori. En 1999, la Empresa Nacional de Ferrocarriles del Perú (ENAFER) cierra sus operaciones en la línea del sur y del suroriente, y se le le otorga la concesión al consorcio Ferrocarril Transandino (FRETRANS), conformado por Containers y Peruval Corp, empresa cuyo dueño es López Aliaga, quien además es copropietario de Peru Rail, em- 
presa encargada de la operación de trenes en la línea Cusco-Machu Picchu. También se hace socio de la transnacional Belmond LTD para formar la compañía Perú Belmond Hotels, que gerencia hoteles en Lima, Cusco y Arequipa, entre ellos, el Belmond Miraflores Park y el Belmond Hotel Monasterio. El currículum de López Aliaga es más largo y turbio, pero lo dicho basta para dejar en claro que es un empresario que hace fortuna con el Estado neoliberal y con sus vínculos a grandes corporaciones internacionales. No es por tanto un tecnócrata que representa al empresariado: es un empresario hijo predilecto del neoliberalismo.

Pasemos ahora al otro gran pilar de su candidatura: el evangelismo. A pesar de que López Aliaga no se ha convertido al evangelismo como Kast y Bolsonaro, es un devoto miembro del Opus Dei que practica el celibato y la mortificación del cuerpo. Y además ha obtenido el apoyo de evangélicos pentecostales y neopentecostales, entre quienes destaca la pastora Milagros Aguayo, referente del movimiento Con Mis Hijos No Te Metas y de los esfuerzos conservadores por erradicar el enfoque de género de la enseñanza escolar. Pero la apuesta de López Aliaga y su grupo no ha sido simplemente capturar el voto evangélico sino el de los cristianos en general. De hecho, como lo explica José Luis Pérez Guadalupe (2021), su público proviene de cuatro segmentos sociales: "a) católicos conservadores (sobre todo de movimientos eclesiales como el Opus Dei. Sodalicio de Vida Cristiana, Neocatecumenado, etc.), b) evangélicos (neo) pentecostales, c) la ultraderecha peruana (que en el Perú se le conoce coloquialmente como la DBA: Derecha Bruta y Achorada), y d) ciudadanos tradicionales (no neceseriamente religiosos) que ven amenazados sus criterios valorativos con los cambios culturales de los últimos años, como la igualdad de género, el lenguaje inclusivo, el posible matrimonio igualitario, etc".

Así como en Chile, Brasil y Costa Rica, hay en Perú la misma coalición entre empresarios neoliberales, conservadores cristianos y conservadores en general, encabezada por un candidato que lucha contra la agenda progresista de la "ideología de género" y que la identifica como parte de un proyecto comunista internacional. De hecho, el mal manejo de la pandemia del Gobierno del presidente Martín Vizcarra fue, para López Aliaga (2021a), "un plan comunista de quebrar la economía, pero a rabiar. Eso dice Marx: para que se cree el nuevo orden marxista, el nuevo orden mundial, se tiene que destruir toda la economía, se tiene que poner en cenizas, y luego construir el paraíso comunista". 
Hay varios tipos de comunistas, pero el que atrae más el odio de López Aliaga es el caviar. Originalmente, el término viene de Francia y se refiere a las personas de izquierda con una situación económica acomodada. Hay muchos otros usos del significante caviar, pero en Perú ha adquirido uno bastante amplio que abarca desde la exalcadesa de Lima Susana Villarán (de la vieja tradición de izquierda), pasando por el presidente de la Corte Interamericana de Derechos Humanos Diego Sayán, a la comentarista política Rosa María Palacios (una neoliberal progresista). López Aliaga (2021b) ha dado dos definiciones cruciales de caviar. La primera: "Es un ser que nace, crece, entra al Estado, gana 15 mil soles sin hacer nada, y luego se reproduce y muere. Y en el medio destroza la actividad privada, destroza a la Iglesia y destroza a las Fuerzas Armadas". El caviar es, así, un comunista con cierto estatus social que tiene acceso al Estado y desde allí atenta contra la economía (la actividad privada), la seguridad nacional (las Fuerzas Armadas) y la cultura religiosa (la Iglesia). En otras palabras, el caviar atenta contra la fantasía de una familianación moderna dirigida por actores tradicionales: empresarios, militares y curas.

Si el caviar es un comunista "de estatus", el comunista de los sectores menos favorecidos de la sociedad es un terrorista (o terruco). El comunismo estaría compuesto por caviares y terroristas, y la campaña de López Aliaga quiso "hacer evidente" los cruces entre los dos. Así, por ejemplo, Neldy Mendoza (la candidata a la vicepresidencia con López Aliaga) llamó "abuelas terroristas" a las mujeres que les inculcan a sus hijas que su desarrollo profesional es más importante que la maternidad, pues entonces estas tenderían a criar mal a sus propias hijas. López Aliaga desautorizó publicamente a su vicepresidenta, pero los trolls de (o cercanos a) su campaña no perdieron la oportunidad de sindicar como "abuelas terroristas" a las congresistas "caviares" Mirtha Vásquez y Rocío Silva Santisteban por promover la legalización del aborto. De este modo los defensores "caviares" de la agenda progresista cultural (las feministas o los seguidores de la "ideología de género") se mutaron en terroristas, cuyo objetivo no era otro que demoler la familia-nación.

La segunda definición es "todo caviar es corrupto" (2021b). Dado que el caviar no tiene capacidad de hacer empresa, "va directamente a la teta del Estado". Este aserto se hace en el contexto del caso Odebrecht, el más grande caso de corrupción del siglo XXI en el Perú. Así como los demás candidatos, López Aliaga repitió como un mantra que el primer problema del Perú es la corrupción. Pero, para él, los principales cómplices de Odebrecht no fueron 
los empresarios peruanos ni los funcionarios neoliberales del Estado sino los caviares. La corrupción pasa así a ser parte del plan comunista por destruir a la familia-nación cristiana y capitalista. Y la gesta de López Aliaga consistía en convocar al pueblo de los emprendedores, los cristianos o, mejor, los emprendedores cristianos, para restaurar los lazos comunitarios contra la elite corrupta de caviares progresistas.

Contra los caviares-terroristas-comunistas-corruptos, López Aliaga proponía "cadena perpetua" y reabrir el Sepa, una colonia penal ubicada en una región aislada de la selva amazónica que antaño inspiraba terror a los disidentes. He aquí el autoritarismo, la "mano dura", pero esta no engancha al pueblo solamente por la admiración a la necesaria firmeza del líder para hacer cumplir la ley sino por la identificación con la mano que responde al agravio. Es decir, a través de la identificación con el líder, el pueblo goza con una venganza liberadora-autoritaria contra esos comunistas que quieren convertir al Perú en Venezuela.

Pero, además, la manera vulgar en que a veces se manifiesta esta pulsión emparienta a López Aliaga con Trump: así como este, aquel se complace en insultar a los periodistas. Mónica Delta es, por ejemplo, "parte de la mermelada" que "vive de los impuestos que tú pagas" y "tiene un montón de fotos amorosas con Vizcarra". Y Juliana Oxenford, quien criticara su plan de viajar a Estados Unidos ni bien fuera elegido presidente para comprar 40 millones de vacunas, es una "ignorante de porquería" a quien le falta "enterarse de lo que pasa en el mundo". En este sentido, la vulgaridad de López Aliaga provee a su público con un punto de identificación pulsional con la transgresión vengativa-liberadora-autoritaria de las normas de corrección política e, incluso, de las viejas normas de decencia, las cuales prohíben insultar a las mujeres, aunque sean "vanidosas" mujeres empoderadas.

Sin embargo, sería mezquino argüir que López Aliaga es simplemente un foco de identificación pulsional. A diferencia de Trump y Berlusconi, cuya imagen oscila entre el ideal del yo (ideal de sacrificio) y el yo-ideal (ideal narcisista), López Aliaga se posiciona más claramente como punto de identificación con el ideal del yo. Él se presenta como un empresario sumamente exitoso que se introduce en la política para salvar a su país (ideal del yo), y su rutina de celibato inhibe su asociación con el consumismo. Pero, además, su trayectoria como empresario, sus vínculos con compañías transnacionales y sus planes para el Perú con visión empresarial han sido claves para convertirlo en el candidato con la tercera más alta votación en el Perú. Inclusive, ha trata- 
do de diferenciarse de Hernando de Soto y Pedro Pablo Kuczynski mediante el argumento de que si bien estos son hombres conocen la ciencia económica, nunca han sido realmente empresarios. Se trata para él de colocarse como la encarnación del ideal del emprendedurismo, quizás el ideal más aceptado en el Perú del siglo XXI.

Asimismo, su larga y exitosa carrera de empresario ayuda a hacer digerible su segunda fantasía-utopía, compartida en sus entrevistas y videos de campaña: "Hay que tener un planeamiento, a dónde queremos llegar. Yo quiero llegar a ser potencia mundial" (López Aliaga 2021c). No sé qué tan literalmente cree la población en esta fantasía, pero responde al deseo de un "pueblo" de individuos emprendedores que se asumen como la fuerza viva de la nación. Es la utopía de la "revolución capitalista", popularizada por Jaime de Althaus, pero que tiene su primer momento teórico con El otro sendero de Hernando de Soto (donde este hace pasar a los informales de la posición proletaria a la de empresarios schumpeterianos, cuyo único obstáculo para crear y sobresalir son las trabas del Estado burocrático), y que luego se materializa en el movimiento Libertad de Mario Vargas Llosa y casi inmediatamente después en el régimen de Alberto Fujimori, cuyo famoso shock o tsunami permitió la aplicación de las reformas liberales en el Perú. De hecho, se podría decir que el referente histórico más reciente de la derecha radical peruana es el golpe del 11 de abril, el que hace posible la Constitución pro-neoliberal de 1993, así como la re-reelección de Fujimori.

Fujimori - hay que decirlo - no es solo un seguidor de Pinochet. Es un líder que rediseñó la matriz pinochetista de la extrema derecha dictatorial para convertirla en un autoritarismo competitivo que persigue los cambios sociales transgrediendo las normas democráticas, pero sin violarlas del todo. Pinochet fue un líder autoritario que gozaba de cierta popularidad, pero Fujimori fue un líder autoritario y populista que fue elegido tres veces en elecciones democráticas. Es cierto que en el 2000 las elecciones fueron amañadas, pero también lo es que, aun así, un amplio sector de la población seguía viendo a Fujimori como un líder que se alzó contra un Estado inepto e indolente que produjo hambre, hiperinflación y que no supo tener "mano dura" contra el terrorismo. La verdad es, por supuesto, otra. Pero la narrativa fantasmática que sostiene tanto a la nación peruana como a la derecha radical es que Fujimori refundó la nación mediante un golpe de Estado que permitió acabar con el terrorismo, la hiperinflación y elevar el nivel de vida de los peruanos. 
Provoca decir que Fujimori es el primer derechista radical de América Latina. No solo porque haya sido populista y autoritario, sino porque en la elección de 1990 fue apoyado por los evangélicos. Sin embargo, estos fueron marginados del poder ni bien él llegó a la presidencia y no se puede decir que el nativismo o los temas de género hayan sido centrales en su campaña o Gobierno. Es más bien su hija quien en los últimos ha asumido una postura socialmente anti-progresista. Desde el 2016 en adelante, Keiko Fujimori ha empezado a hacer suyos los temas del aborto y contra el enfoque de género, y en el 2021 le ha disputado el voto cristiano y/o conservador a López Aliaga. Pero no quiero ocuparme de ella en este escrito. Basta con señalar que hay un relativamente amplio espacio en la política peruana para la derecha radical que tiene como matriz velada el autogolpe de Alberto Fujimori y, aún más velada, el golpe de Augusto Pinochet. Pero no basta con remitirse a esta matriz para ser de derecha radical. Hay que poder apelar a un pueblo mediante la etnia, la religión o la tradición cultural. Y con Alberto Fujimori no hubo mucho de eso. La derecha radical en Perú es, por tanto, un fenómeno que comienza en la segunda década del siglo XXI.

Resumo para empezar a concluir: tenemos, en López Aliaga, dos deseos con sus respectivas utopías. La primera es el retorno a una época mítica previa a los partidos comunistas en que existía una familia-nación cristiana tutelada por actores tradicionales como empresarios, militares y eclesiásticos. Es la utopía de la república aristocrática. La segunda es un salto hacia adelante en que Perú se convierte en una potencia económica y los peruanos emprendedores en ciudadanos del mundo. Ambas utopías pueden sintetizarse, contradecirse o actuar en tensión. Pero queda claro que ambas tienen como enemigo al comunista (ya sea caviar o terrorista), quien pretende destruir lo avanzado (el modelo neoliberal) y a la vez lo que permanece (los valores cristianos). He aquí una diferencia crucial entre López Aliaga y los candidatos de la derecha radical en Europa y Estados Unidos. Mientras que estos se basan en una utopía pasadista de obreros y patrones blancos en el capitalismo fordista, López Aliaga combina la utopía pasadista de la república aristocrática cristiana con otra en que Perú deviene potencia mundial. Algo de esto puede haber también en el "Make America great again" ("Hacer a Estados Unidos grande otra vez") de Trump. Aunque en Perú no se trata de restaurar ninguna grandeza pasada, sino de "Make Peru great for the first time" ("Hacer a Perú grande por primera vez”). 
El enemigo de las dos utopías es, por supuesto, el comunista (el terrorista y el caviar). Pero este nombre se separa de cualquier análisis político medianamente serio para designar a quien se oponga a la república aristocrática en camino a ser potencia mundial. Contra el comunista se puede dar rienda suelta a toda la pulsión vengativa y López Aliaga está obligado no solo a encarnarla sino a mostrarla. El candidato tiene que mostrar firmeza para sostener el deseo y la fantasía, pero también impaciencia, rabia y odio contra los obstáculos, como lo haría "cualquiera de nosotros". Y he aquí una gran falencia del candidato de Renovación Popular: a pesar de que se esforzaba en mostrar lo anterior, le faltaba la voz. Nada fue peor para sus aspiraciones presidenciales que su incapacidad para transmitir fuerza y firmeza en el habla. Nada peor, es decir, que su incapacidad para convertir la voz en objeto de identificación pulsional liberadora-autoritaria.

Finalmente, todo lo anterior se articula en la forma del delirio paranoico que intenta curar al pueblo conservador y capitalista de las fuerzas disgregadoras de los comunistas que fomentan que lo femenino se salga de su lugar en el mundo y que, además, obstaculizan el tren neoliberal. De hecho, la teoría conspirativa de los comunistas genocidas (por el manejo de la pandemia) y fraudulentos (por el manejo de las elecciones), que operan bajo los designios del Foro de Sao Paulo, ayudó a instaurar en la segunda vuelta, y en el posterior cuestionamiento de sus resultados, la idea de que si Pedro Castillo llegaba a Palacio de Gobierno sería básicamente el fin del Perú. Es más, no sería falso argüir que, en la segunda vuelta y después, la campaña de Keiko Fujimori y la mayoría de los medios de comunicación hicieron suyos buena parte de la interpretación delirante de López Aliaga sobre la familia-nación peruana amenazada por los comunistas.

Queda por verse si este delirio concluye en un golpe duro de la extrema derecha, aunque por ahora todo parece manejarse dentro de la lógica del "golpe blando" o del "golpe constitucional". Pero más allá del destino particular del Perú, lo que está en juego teóricamente es si todavía se mantiene la tesis de que el delirio paranoico se halla acotado en la derecha radical por la institucionalidad democrática y los acuerdos internacionales.

Termino con tres reflexiones puntuales.

Uno: Cas Mudde (2019) define la derecha radical en Europa y Estados Unidos como nativista, autoritaria y populista. Pero la derecha radical en Perú y América Latina es más bien anti-feminista-LGTBI, autoritaria y populista. Aunque Mudde (2019) pone énfasis en el nativismo, la derecha radical en 
Europa y Estados Unidos puede ser también anti-feminista-LGTBI. Y, por eso mismo, tomando en cuenta la derecha radical latinoamericana, habría que preguntarse si este fenómeno mundial no es principalmente una reacción patriarcal contra un goce femenino que se sale de su lugar acostumbrado y se ubica de otro modo en el espacio público y los cuerpos masculinos.

Dos: si la derecha radical en América Latina se diferencia de la de Europa y Estados Unidos en que es abiertamente neoliberal y en que su matriz histórica no es tanto el fascismo como el colonialismo y el neoliberalismo (Pinochet y Fujimori), deberíamos abandonar el concepto de posfascismo de Traverso (2018), así como el de fascismo clásico de Toscano (2020), para referirnos al fenómeno político en cuestión. Quizás lo más prudente por el momento sea asumir el término derecha radical de Cas Mudde (2019), pero haciendo en él una precisión clasificatoria: marcar una diferencia entre la derecha radical posfascista (la europea) y la derecha radical colonialista-pospinochetista (la latinoamericana). Pero, también, dado que la derecha radical en Europa y Estados Unidos no parece romper claramente con el neoliberalismo, habría que indagar si la derecha radical pospinochetista es más importante en Occidente de lo que se piensa.

Finalmente: el delirio paranoico nativista y/o patriarcal permite lidiar con la angustia de que la comunidad se deshace y que "todo lo sólido se desvanece en el aire". Pero este delirio en Perú y América Latina encierra una paradoja: por un lado, pretende resolver las fuerzas disgregadoras acoplándose a la familia-nación conservadora, mientras que, por el otro, apuesta por políticas neoliberales que tienden a introducir en el país nuevas fuerzas disgregadoras (o como dirían Deleuze y Guattari, nuevas fuerzas de descodificación esquizoide). Y lo que habría que pensar como hipótesis es que si esta paradoja se sostiene en el tiempo, la intensificación de las políticas neoliberales puede concluir en una intensificación del conservadurismo sociopolítico que sobrepase los límites de la derecha radical y concluya en una extrema derecha abiertamente posdemocrática. 


\section{Referencias bibliográficas}

Arantes, M. 2020. Brasil: una política exterior contra el "marxismo cultural". Nueva Sociedad. https://bit.ly/3xU5zVG

Arias, E. 2018. Análisis: Fabricio Alvarado y el nuevo "dream team” económico. Voces Nuestras. Centro de Comunicación. https://bit.ly/3eulH81

Badiou, A. 2020. Badiou contra Trump. Buenos Aires: Capital intelectual.

Costa, S. y Badia I Dalmases, F. 2018. Bajada de un ciclo que termina. Desigualdad persistente: el controversial legado de la "marea rosa". Envío, (432). https://www.envio. org.ni/articulo/5457

Deleuze, G. 2005. Derrames. Entre el capitalismo y la esquizofrenia. Buenos Aires: Cactus.

Deleuze, G. y Guattari, F. 1972-3. L'anti-Oedipe. Capitalisme et schizofrenie. París: Minuit.

Freud, S. 1955a. Psicología de las masas y análisis del yo. Obras completas (vol. 18). Buenos Aires: Amorrortu Editores.

Freud, S. 1955b. El malestar en la cultura. Obras completas (vol. 21). Buenos Aires: Amorrortu Editores.

De Olivera de Castro, H. C. y Vizcarra Castillo, S. I. 2020. Una democracia frágil sin valores democráticos: Brasil en el siglo XXI. Política y Sociedad, 27 (3). 671-692. Madrid.

Dólar, M. 2007. Una voz y nada más. Buenos Aires: Manantial.

Geva, D. 2021. Orban's Ordonationalism as Post-Neoliberal Hegemony. En Theory, Culture and Society. Special Issue: Post-neoliberalism? https://bit.ly/3in81Mh

Indart, J. C. 1999. El peso de los ideales. Buenos Aires: Paidós.

Kahhat, F. 2021. ¿Por qué crece la derecha radical en América Latina? América Economía. https://bit.ly/2Uf0nx2

Kahhat, F. 2019. El eterno retorno. La derecha radical en el mundo contemporáneo. Lima: Planeta.

Lacan, J. 2003. La agresividad en psicoanálisis. Escritos 1. Buenos Aires: Siglo XXI Editores.

Levitsky, S. y Way, L. A. 2004. Elecciones sin democracia. El surgimiento del autoritarismo competitivo. Estudios Politicos, (24), 159-176.

Linz, J. 2000. Totalitarian and Authoritarian Regimes. Londres: Lynne Rienner.

López Aliaga, R. 2021a. Rafael López Aliaga habla de las vacunas y la cuarentena. UCI. https://www.youtube.com/watch?v=hnsQ0pd7WMQ 
López Aliaga, R. 2021b. Todo caviar es corrupto. Sin Medias Tintas. https://www.youtube.com/watch?v=ZDvvvxU3-PQ

López Aliaga, R. 2021c. Somos potencial mundial. Rafael López Aliaga (Facebook oficial). https://www.facebook.com/watch/?v=488567472179248

Lynch, N. 2020. La derecha peruana de encomenderos a neoliberales, pero siempre encomenderos. Discursos del Sur, (6), 47-73.

Maier, H. 2007. Political Religion: A Concept and its Limitations. Totalitarian Movements and Political Religions, 8 (1), 5-16.

Marx, K. y Engels, F. 2014. Manifiesto comunista. Santiago de Chile: Espartaco.

Millas, D. 2015. El psicoanálisis pensado desde la psicosis. Buenos Aires: Grama.

Mudde, C. 2019. The Far Right. Cambridge: Polity Press.

Oficina Nacional de Procesos Electorales (ONPE). 2021. Presentación de votos válidos. Elecciones generales y parlamento andino 2021. Lima. https://bit.ly/3rhRm1Z

Olterman, P. 2014. Heidegger's "black notebooks" reveal antisemitism at core of his philosophy. The Guardian. https://bit.ly/2UNdZ2h

Payne, S. G. 2014. El fascismo. Madrid: Alianza Editorial.

Paxton, R. O. 2004. The Anatomy of Fascism. Nueva York: Random House.

Papa, G. 2004. La herencia del neoliberalismo en América Latina y los márgenes de maniobra de los Gobiernos progresistas. Análisis y propuestas. Montevideo: Friedrich Ebert Stiftung.

Pereira da Silva, F. 2018. La bajada de la marea rosa en América Latina. Una introducción. Revista de la Red de Intercátedras de Historia de América Latina Contemporánea, 5 (8), 59-66.

Pérez Guadalupe, J. L. 2021. López Aliaga: el Bolsonaro peruano. Revista Testimonio. Boletín del instituto de Estudios Social Cristiano, (133). https://bit.ly/3Birnwi

Polo Blanco, J. 2019. ¿Fue el fascismo una reacción anticapitalista? En A. A. Adoración Guamán y S. Martín (Dirs.). Neofascismo. La bestia neoliberal (pp. 48-76). Madrid: Siglo XXI Editores.

Stavrakakis, Y. 1999. Lacan and The Political. Nueva York: Routledge.

Stefanoni, P. 2021. ¿La rebeldia se volvió de derecha? Cómo el antiprogresismo y la anticorrección política están construyendo un nuevo sentido común (¿y por qué la izquierda debería tomarlos en serio?). Buenos Aires: Siglo XXI Editores.

Stumpf González, R., Baquero, M. y Mello Grohmann, L. G. 2020. ¿Nueva derecha o vino viejo en odres nuevos? La trayectoria conservadora en Brasil en el último siglo. Politica y Sociedad, 57 (3), 647-670. Madrid.

Toscano, A. 2020. Apuntes sobre el fascismo tardío. Pléyade. Revista de humanidades y ciencias sociales, (25), 29-50. 
116 | Discursos Del Sur / Juan Carlos Ubiluz Raygada

Traverso, E. 2018. Las nuevas caras de la derecha. Buenos Aires: Siglo XXI Editores.

Zapata, A. 2016. Pensando a la derecha: historia intelectual y política. Lima: Planeta.

Zizek, S. 2020. A Left that Dares Not Speak Its Name. 34 Untimely Interventions. Cambridge: Polity Press. 